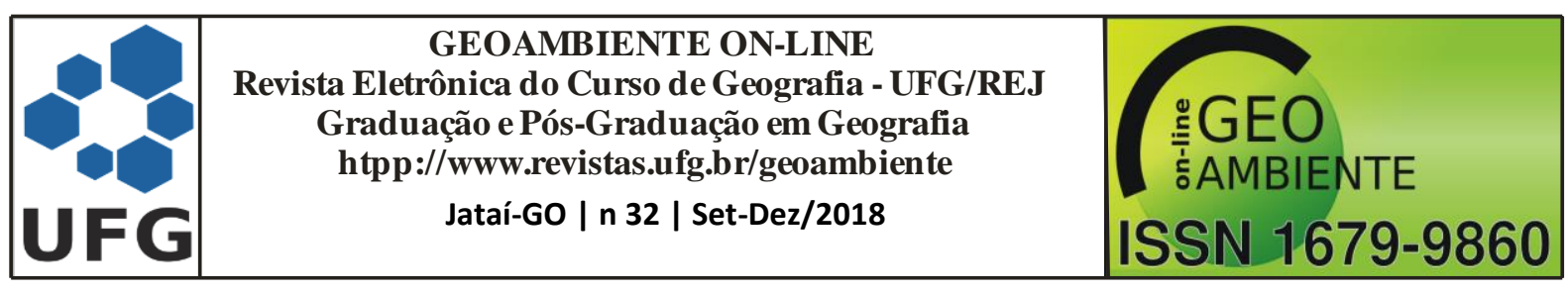

\title{
PRODUÇÃO DO ESPAÇO PELA EXPLORAÇÃO DO GNAISSE NA COMUNIDADE DA VILA RENASCER EM PETROLINA-PE
}

Fredson Pereira da Silva ${ }^{1}$ "Mauricio de Sousa Rodrigues", Geraldo Jorge Barbosa de

\author{
Moura $^{3}$, Carlos Alberto Batista dos Santos ${ }^{4}$
}

(1 - Universidade do Estado da Bahia - UNEB, Mestrando em Ecologia Humana e Gestão Sócioambiental, fredson_psilva@ hotmail.com, 2 - Universidade de Pernambuco - Campus Petrolina, Graduando em Geografia, mdsrpesquisas@gmail.com, 3 - Universidade Federal Rural de Pernambuco, Docente do departamento de Biologia, geraldojbm@ yahoo.com.br, 4 Universidade do Estado da Bahia, Docente - Departamento de Tecnologia e Ciências Sociais, cacobatista@yahoo.com.br).

Resumo: A produção do espaço é fruto da relação da sociedade/natureza, esse processo desenvolve no tempo e no espaço uma forma que imprime símbolos, costumes e tradições sociais existentes no processo de (re) produção da vida no espaço geográfico. O objetivo deste estudo é compreender o processo de transformação do espaço pela exploração da mineração do gnaisse na comunidade da Vila Renascer em Petrolina, Pernambuco, Nordeste do Brasil. A pesquisa foi norteada pelo método qualitativo-quantitativo, a metodologia utilizada foi através de levantamento bibliográfico em livros, artigos e dissertações, seguida de pesquisa de campo, entrevistas, documentos e registos fotográficos, o que possibilitou a análise da produção do espaço a partir das atividades econômicas desenvolvidas no processo de formação da Vila Renascer que era essencialmente agrícolas, produzindo feijão, milho, mandioca e carvão vegetal. As primeiras extrações minerais eram processos rústicos, sendo os tipos de rochas selecionadas de forma manual, processo que atendia às necessidades dos moradores locais naquele momento. A transformação espacial da comunidade aconteceu a partir da mineração do gnaisse. Atualmente a mesma passa por dificuldades devido à ausência de um plano diretor para ordenar a mineração, o que implicou na transformação radical do território.

Palavras-chave: Produção do espaço, Exploração do gnaisse, Impactos, Vila Renascer.

\footnotetext{
Artigo recebido para publicação em 23 de Fevereiro de 2018

Artigo aprovado para publicação em 26 de Novembro de 2018
} 


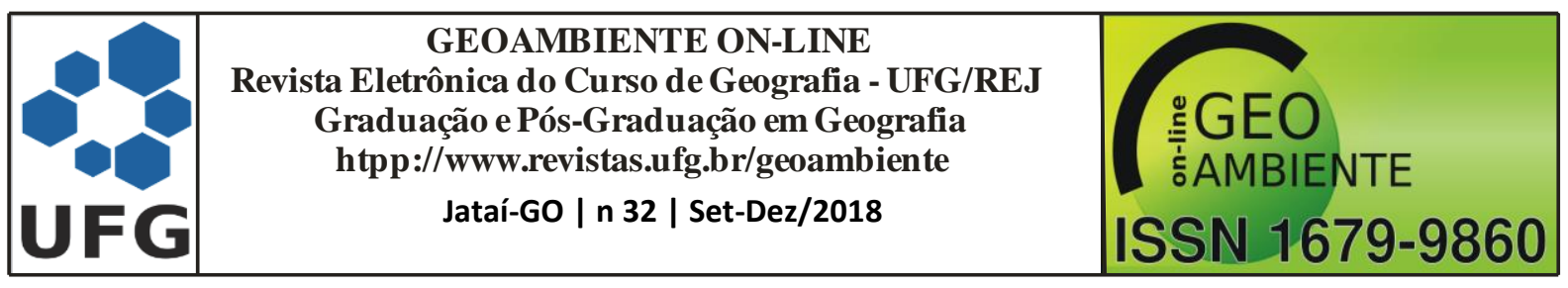

\section{PRODUCTION OF THE SPACE FOR THE EXPLORATION OF GNAISSE IN THE VILA RENASCER COMMUNITY IN PETROLINA-PE}

Abstract: The production of space is the result of the relationship between society and nature, and this process develops in time and space a form that imprints social symbols, customs and traditions in the (re) production of life in geographic space. The objective of this study is to understand the process of space transformation by exploration of gneiss mining in the community of Vila Renascer in Petrolina, Pernambuco, Northeast Brazil. The research was guided by the qualitative-quantitative method, the methodology used was through a bibliographical survey in books, articles and dissertations, followed by field research, interviews, documents and photographic records, which made it possible to analyze the production of space from the economic activities developed in the process of formation of Vila Renascer, which was essentially agricultural, producing beans, maize, cassava and charcoal. The first mineral extractions were rustic processes, and the types of rocks were selected manually, a process that met the needs of the local inhabitants at that time. The spatial transformation of the community happened from the mining of the gnaisse. Currently, it is experiencing difficulties due to the lack of a master plan to order the mining, which implied a radical transformation of the territory.

Keywords: Production of space, Exploration of the gneiss, Impacts, Vila Renascer.

\section{PRODUCCIÓN DEL ESPACIO POR LA EXPLOTACIÓN DEL GNAISSE EN LA COMUNIDAD DE LA VILA RENASCER EN PETROLINA-PE}

Resumen: La producción del espacio es fruto de la relación de la sociedad / naturaleza, ese proceso desarrolla en el tiempo y en el espacio una forma que imprime símbolos, costumbres y tradiciones sociales existentes en el proceso de (re) producción de la vida en el espacio geográfico. El objetivo de este estudio es comprender el proceso de transformación del espacio por la explotación de la minería del gnaisse en la comunidad de Vila Renascer en Petrolina, Pernambuco, Nordeste de Brasil. La investigación fue orientada por el método cualitativo cuantitativo, la metodología utilizada fue a través de levantamiento bibliográfico en libros, artículos y disertaciones, seguida de investigación de campo, entrevistas, documentos y registros fotográficos, lo que posibilitó el análisis de la producción del espacio a partir de las " las actividades económicas desarrolladas en el proceso de formación de Vila 


\begin{tabular}{|c|c|c|}
\hline & $\begin{array}{c}\text { GEOAMBIENTE ON-LINE } \\
\text { Revista Eletrônica do Curso de Geografia - UFG/REJ } \\
\text { Graduação e Pós-Graduação em Geografia } \\
\text { htpp://www.revistas.ufg.br/geoambiente } \\
\text { Jataí-Go | n } 32 \text { | Set-Dez/2018 }\end{array}$ & $\begin{array}{c}\text { : GEO } \\
\text { G.AMBIENTE } \\
\text { G }\end{array}$ \\
\hline
\end{tabular}

Renascer que era esencialmente agrícolas, produciendo frijoles, maíz, mandioca y carbón vegetal. Las primeras extracciones minerales eran procesos rústicos, siendo los tipos de rocas seleccionadas de forma manual, proceso que atendía a las necesidades de los habitantes locales en aquel momento. La transformación espacial de la comunidad se produjo a partir de la minería del gnaisse. Actualmente la misma pasa por dificultades debido a la ausencia de un plan director para ordenar la minería, lo que implicó en la transformación radical del territorio.

Palabras-clave:Producción del espacio, Explotación del gnaisse, Impactos, Vila Renascer.

\section{Introdução}

A produção do espaço é fruto do movimento do homem no meio desde os tempos primitivos, e a transformação deste espaço é resultado da utilização de técnicas de manejo e extração de recursos naturais para garantir sua subsistência, neste sentido, a paisagem pode ser entendida como realidade física ou como construção social, pois se encontra em constante transformação, mediada pelos costumes sociais de um determinado local, evoluindo entre a natureza e a sociedade, sendo concebida simultaneamente como natureza-objeto e naturezasujeito (TRES, REIS, SCHLINDWEIN, 2011).

Durante todo o processo de transição do nômade que vivia dos recursos ofertados abundantemente pela natureza e que se deslocava com a escassez para outras áreas, para o homem que passou a viver fixo em uma área viável para através do trabalho no solo, colher e armazenar sua produção afirma agricultor e constitui o espaço para sua manutenção, modificando a paisagem (FURTADO et al., 1994).

Para Carlos (2007), ao se estabelecer em uma determinada região, o homem até então nômade desenvolve um elenco de técnicas agrícolas elaboradas diante das necessidades de reprodução da vida, o que garante um caminho para formação dos primeiros aglomerados humanos.

Diante disto, este estudo busca compreender o processo de transformação do espaço pelos produtores agrícolas e extratores de minérios da Vila Renascer em Petrolina, Pernambuco, Nordeste do Brasil. A pesquisa foi norteada pelo método qualitativoquantitativo, como metodologia a pesquisa bibliográfica e pesquisa de campo com realização 


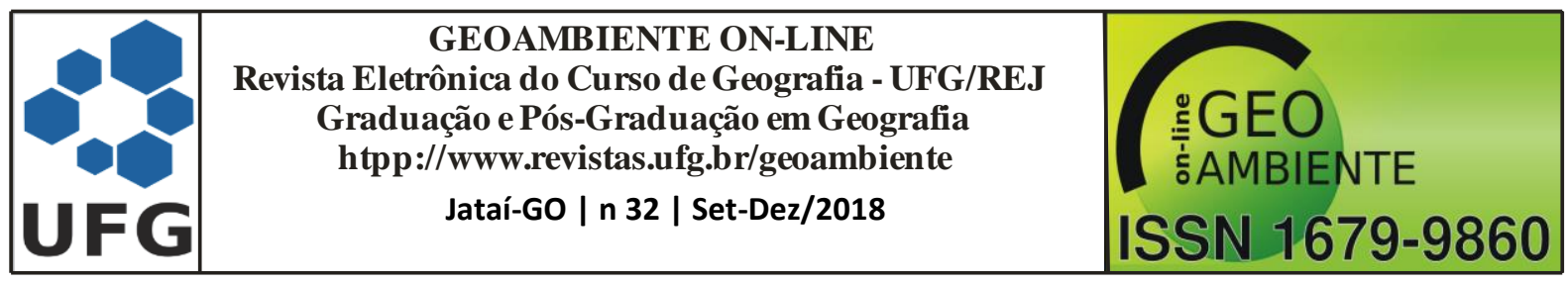

de registros fotográficos e entrevistas com fins de verificar as condições de moradia e os impactos sociais e ambientais.

O artigo está distribuído em três seções: a primeiracom foco no processo de produção dos primeiros aglomerados urbanos na história, apresenta um pouco do processo de produção desses espaços a partir das condições de exploração do meio para sua reprodução e desenvolvimento das espécies. A segunda apresenta a ocupação histórica territorial no Submédio São Francisco, abordando o povoamento do Vale do São Francisco a partir da colonização e os nativos que habitavam. E por último, apresentamos uma análise da paisagem a partir da implantação da mineração na Vila Renascer em Petrolina - PE, destacando as transformações e os impactos sociais e ambientais, também a alteração da paisagem local através da exploração da mineração na Vila Renascer, Petrolina - PE.

\section{Processo de produção dos primeiros aglomerados urbanos na história}

As primeiras cidades vão aparecer onde a agricultura se encontra em desenvolvimento, primeiramente na Ásia e logo mais tarde em parte da Europa. As condições também dos recursos naturais foram importantes, pois a sociedade buscava ocupar áreas às margens de rios como o Tigre, Nilo e Eufrates, que possuíam ao seu redor solos férteis para o plantio.

As cidades mais antigas são datadas por volta do ano de 12.000 a 10.000 A.C., na região do Oriente: Israel e Palestina que surgiram no período neolítico, em 5.000 A.C., e denominaram as primeiras povoações Kist, Ur e Uruk (CARLOS, 2007) (Tabela 01).

Tabela 01: As cidades mais antigas da história da humanidade.

\begin{tabular}{|c|c|c|c|}
\hline CIDADE & PAÍS ANTIGO & PAÍS ATUAL & ÉPOCA DE ORIGEM \\
\hline Jericó & Canaã & Jordânia & 5000 a.C. \\
\hline $\mathrm{Ur}$ & Babilônia & Iraque & V Milênio \\
\hline Uruk & Babilônia & Iraque & V Milênio \\
\hline Susa & Elam & Pérsia & 4000 a.C. \\
\hline Hierakompolis & Egito & Egito & 4000 a.C. \\
\hline Kich & Babilônia & Iraque & Início do IV Milênio \\
\hline Nipur & Babilônia & Iraque & ” \\
\hline Eridu & Babilônia & Iraque & " \\
\hline Lagasch & Babilônia & Iraque & IV Milênio \\
\hline Anau & Rússia & 3.500 a.C. & \\
\hline Tróia & & Turquia & 3500 a.C. \\
\hline Mohenjo-Daro & & Paquistão & 3000 a.C. \\
\hline Mênfis & Egito & Egito & 2850 a.C. \\
\hline Roma & & Itália & 2700 a.C. \\
\hline
\end{tabular}




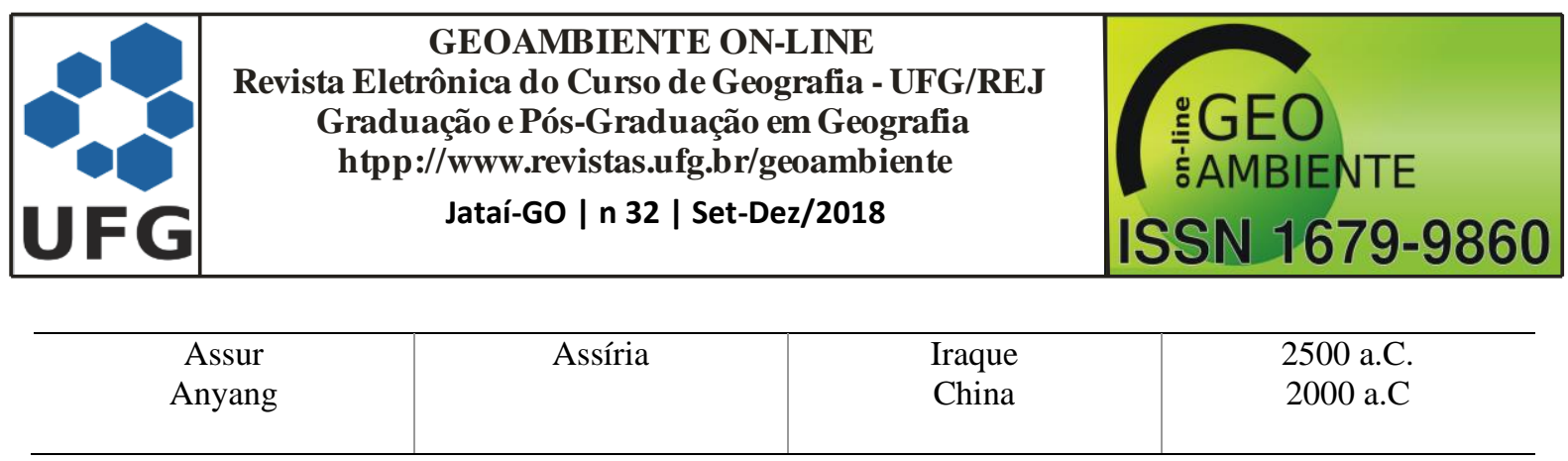

Fonte: Adaptado de Schneider (1965).

Segundo Carlos (2007, p. 56) “a cidades nascem dos papéis que desenvolvem, num determinado momento da história da humanidade e ao longo da história, tomam formas e conteúdos diversos, de acordo com suas características, ganhando expressividade, tendo sua identidade nas suas funcionalidades. Surgem assim, as cidades industriais, culturais, comerciais, administrativas ou políticas.

Em dado momento histórico o feudalismo se apresenta como solução ao modo de produção dependente da agricultara. Esse sistema origina uma estrutura de classes onde a riqueza é garantia da propriedade da terra, sendo dividida e hierarquizada entre a nobreza, a igreja e outras autoridades. O novo modelo destina a população a viver dependente ou independente da agricultura, com a produção toda realizada nos feudos dos quais os servos adquiriam títulos para produzir, e os pagamentos efetuados com parte da colheita (CARLOS, 2007).

Ainda segundo este autor o novo modo de produção inviabilizava os contatos externos, pois era autossuficiente quer seja suprindo as necessidades básicas da alimentação, vestiário ou mobiliários. O bloqueio comercial entre ocidente e oriente pelo mediterrâneo afetou a dinâmica econômica das cidades que necessitavam manter a circulação de utensílios e outros produtos, assim, apenas algumas cidades romanas conseguiram sobreviver (CARLOS, 2007).

No início do século XI com o fim do comercio mediterrâneo a presença dos burgos povoados de mercadores que produziam artesanatos para comercialização - desponta o comércio ao redor dos feudos (COSTA, 2011).

Neste período, a Igreja Romana se utiliza das cruzadas para conquistar a terra santa e unificar os territórios. A indústria que antes era tradicional ganha expressividade com as novas técnicas para a agricultura, o boi é substituído pelo cavalo com a introdução do arado pesado. A produção excedente pode ser trocada em moeda entre artesãos que a partir deste momento passam a viver de seu oficio (RIOS, 2011). 


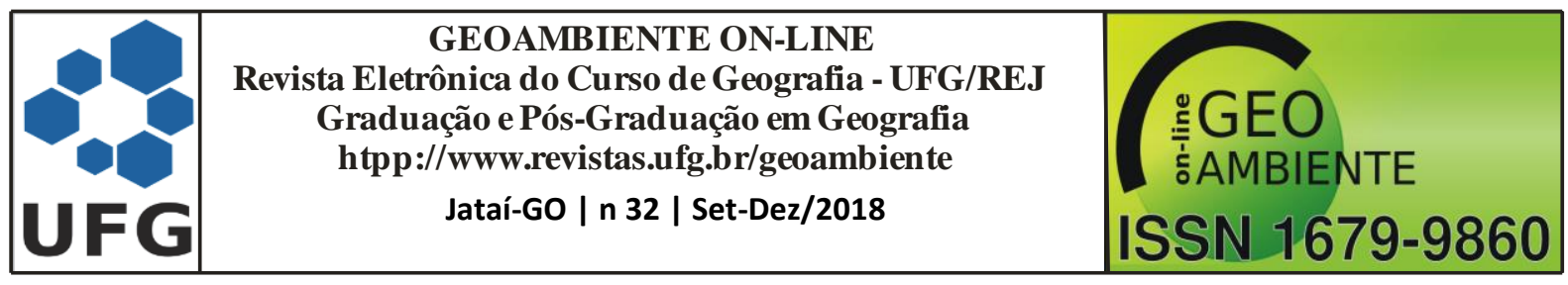

Antes da chegada dos portugueses a região das caatingas, no interior das chamadas terras descobertas, eram habitadas pelos índios Cariris, que vieram expulsos do litoral pelos Tupis, numa disputa pelas terras férteis (ANDRADE, 2002).

Até então os portugueses não tinham desbravado as caatingas, que permaneciam repletas de abundância dos recursos naturais, os povos nativos que aí viviam, viviam da caça, pesca, e coleta de produtos vegetais, quando esta oferta diminuía buscava-se outras áreas. No litoral começava a escravidão dos índios, a resistência e a luta contra os portugueses, muitos tupis fugiram para o interior e passaram ocupar a região a margem do rio Opará (GONÇALVES, 1997).

No dia 04 de Outubro de 1501, a expedição de Américo Vespúcio batizou o Opará como o nome de São Francisco, devido ao costume da época de utilizar o nome dos santos para lugares e terras descobertos. Os nativos desconheciam o nome, para eles era o rio Opará.

Durante as invasões dos territórios indígenas, os portugueses descobriram o ouro, que despertou mais ainda interesse do rei pelo Brasil para explorar o interior das terras descobertas onde se supunha encontrariam diversos minerais preciosos. Sobre isso Gonçalves (1997), afirma que,

O rei passou a incentivar expedições ao interior do Brasil, a fim de levantar as condições e as possibilidades de riqueza do imenso território da colônia. Os portugueses, ávidos por riqueza, empreenderam, às próprias custas, suas investidas sertão a dentro. Organizados em bandos, sob uma chefia, partiam de São Vicente, Salvador e Olinda (GONÇALVES, 1997, p.13).

Nessas expedições muitos morreram devido às condições adversas do ambiente inóspito das florestas tropicais, assolados pela fome, doenças e pelas guerrilhas entre os índios. Assim, tomando conhecimento da possibilidade de obter riqueza na região os portugueses tentam outras expedições com o intuito de aproximação aos nativos para localizarem as possíveis riquezas da região (GONÇALVES, 1997).

As expedições permaneceram na região até aproximadamente 1640, na busca de prata e outros minerais preciosos, porém sem sucesso, durante este tempo os portugueses acumularam um vasto conhecimento sobre a região da caatinga. Os indígenas revelaram uma grande riqueza da região: a agricultura, diante das possibilidades climáticas, solo e o transporte até o litoral, os portugueses passam a escravizar os índios para trabalhar na lavoura (GONÇALVES, 1997). 


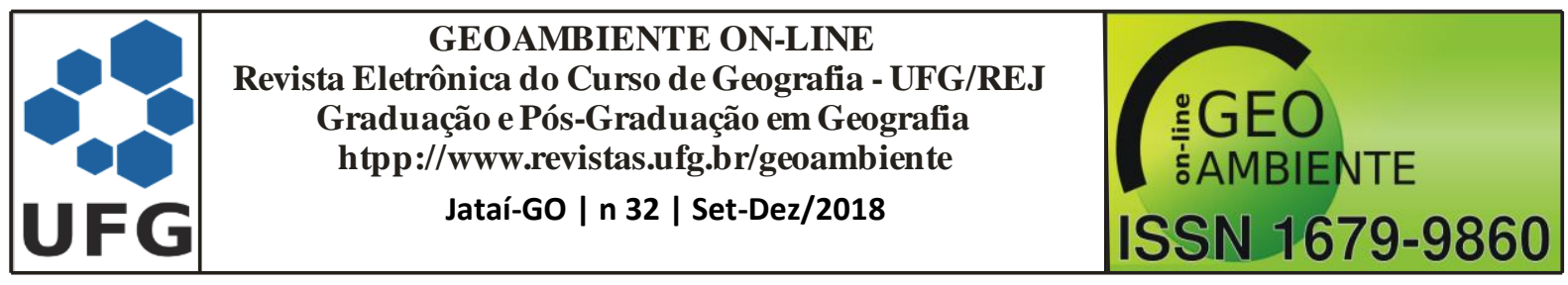

A partir da segunda metade do século XVI, o litoral nordestino, por seu clima, qualidade do solo e facilidade de transporte, caracterizou-se como área de produção de gêneros agrícolas exportáveis, principalmente o açúcar (GONÇALVES, 1997, p.15). A introdução da cana-de-açúcar no litoral necessitava de mão de obra, a implantação de currais pelos Garcia d'Ávila surgia para criação de gado na região do São Francisco para abastecer os engenhos com boi para a tração, a carne e couro. A família Garcia d’Ávila grandes proprietáriosde terras, através do regime de sesmarias aumentava o território para expansão da pecuária.

A pecuária se consolidou na região do São Francisco na década de 1640. Ao contrário das atividades de caça, a criação de bois exigia um mínimo de estrutura e requeria ocupação efetiva do espaço (GONÇALVES, 1997, p.20). Os vaqueiros passam a tomar conta de todo o gado na região para manter a criação livre de ataques entre dos índios, das onças e de doenças.

A influência da família Garcia d’Ávila fez com que a pecuária se espalhasse rapidamente pelos estados da Bahia, Pernambuco, Piauí e Rio Grande do Norte, saturando com a demanda de gado o parco mercado, a região sofreu bastante com o declínio da agricultura. $\mathrm{Na}$ Bahia as tropas que vinha do Piauí cortavam a região e paravam com o gado na Passagem do Juazeiro para repousar, antes de seguir viagem até a capital (GONÇALVES, 1997).

Moradores que resistiram à margem do rio tentavam tocar a vida com a passagem dos tropeiros para comercializar alguns utensílios, a agricultura é única alternativa para a região castigada pela rala vegetação agora ocupada pelos bois, a escassez de pastagem não garantia a alimentação dos animais deixando a produção mais cara. Dessa forma inviabilizando a pecuária a partir desta realidade, recursos vindos para a região através dos governos do Pernambuco e Bahia garantem a implantação da agricultura às margens do rio (GONÇALVES, 1997).

A concentração de pessoas na margem do rio São Francisco e o plantio de legumes e grãos ajudaram, junto com a produção artesanal do barro e do couro, dinamizando desta forma a vida dos que resistiram às dificuldades da região. A farta produção de verduras foi desenvolvendo a vida nas margens, nos períodos de cheias, garantindo o sustendo dos pequenos núcleos humanos que surgiam (GONÇALVES, 1997). 


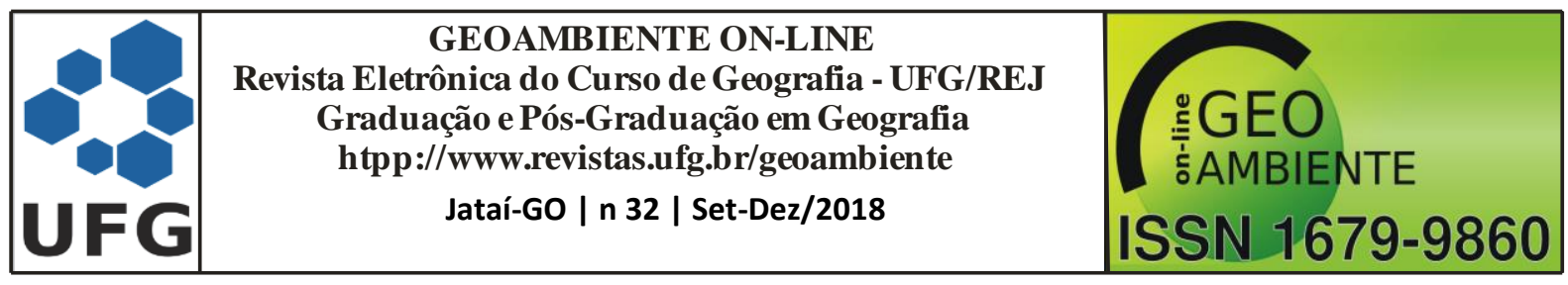

Neste processo, começam a aparecer alguns aglomerados humanos nas fazendas do submédio do rio São Francisco, com características urbanas, tendo um modesto centro de comercialização de pequenas produções e o sistema de coronelismo, com a força bruta prevalecendo nas decisões políticas (GONÇALVES, 1997).

No final do século XIX ainda com uma realidade marcada pelo fracasso da pecuária que não sustentava a economia local devido à diminuição pastoril para alimentação dos bois rotulados de terceira qualidade. As embarcações e o caminhão traçam caminhos para a população que passa a migrar para grandes cidades em busca de emprego (GONÇALVES, 1997).

$\mathrm{O}$ século $\mathrm{XX}$ abre portas para o isolamento geográfico que a região portava em seus ombros, a constituição de muitos papéis principalmente o acesso à educação, foi fundamental para atrair estudantes de cidades vizinhas. A iniciativa do primeiro bispo Dom Malan cria uma escola em Petrolina, e os olhares dos grupos humanos se voltam para a região.A criação de instituições de ensino promove a abertura de novos horizontes na visão política do submédio São Francisco, sendo formada nesse período a Comissão do Vale do São Francisco, que teve como proposta, romper o distanciamento dos recursos necessários ao desenvolvimento local(GONÇALVES, 1997). Estudos realizados na região determinaram grande potencial no ramo hidroelétrico e de transmissão, as técnicas para irrigação e as culturas foram importantes na obtenção de renda, para Gonçalves,

\footnotetext{
A introdução do cultivo de cebola na década de 1940 foi muito importante para a modificação da visão da agricultura, ainda que tal cultivo tenha se circunscrito a pequenas e isolada áreas. Alguns comerciantes do submédio São Francisco descobriram nela um produto da fácil comercialização e de perspectivas lucrativas (GONÇALVES, 1997, p.130).
}

Diante das transformações ocorridas pela globalização, pode-se percebe uma profunda mudança na relação cidade/campo, sendo as transformações do espaço rural devido a uma projeção econômica no contexto da reestruturação produtiva, alterando os papeis do campo, pois a produção que antes era de subsistência, passa a ter um novo modelo de acordo com a demanda do mercado internacional.

A continua industrialização das áreas rurais alterou expressivamente as relações de trabalho e de produção agrícola, definindo uma nova estrutura socioeconômica e política apoiada por programas e instituições governamentais como estratégia de 


\begin{tabular}{|c|c|c|}
\hline & $\begin{array}{c}\text { GEOAMBIENTE ON-LINE } \\
\text { Revista Eletrônica do Curso de Geografia - UFG/REJ } \\
\text { Graduação e Pós-Graduação em Geografia } \\
\text { htpp://www.revistas.ufg.br/geoambiente } \\
\text { Jataí-Go | n } 32 \text { | Set-Dez/2018 }\end{array}$ & $\begin{array}{c}\text { :GEO } \\
\text { G. AMBIENTE } \\
\text { G }\end{array}$ \\
\hline
\end{tabular}

atuação do governo brasileiro para a inserção do capitalismo mundial no campo (OLIVEIRA, SANTOS, 2009, p.10).

O polo Petrolina-Juazeiro engloba vários Perímetros Irrigados. Na margem esquerda do rio São Francisco, município de Petrolina (PE), temos os Projetos Senador Nilo Coelho e Bebedouro. Na margem direita do rio, município de Juazeiro-BA, estão sediados os Projetos Mandacaru, Curaçá, Tourão e Maniçoba, [...] que receberam vários investimentos para seu desenvolvimento econômico através de programas do Governo, pois a região do Vale do São Francisco possui condições climáticas e solos adequados que proporcionam a implantação da fruticultura irrigada. Neste sentido, com a produção de frutas tropicais como manga e uva para o comercio exterior e destinado aos países: Estados Unidos, Japão e Europa (ORTEGA, SOBEL, 2010).

O desenvolvimento das pesquisas no Vale do São Francisco tem atingido um alto
grau, a exemplo das uvas sem sementes, um referencial a mais no concorrido
mercado de frutas frescas. Estas, são produzidas no Projeto Senador Nilo Coelho,
por grandes empresários que tem garantia de mercado na Europa, Estados Unidos e
Japão, enquanto o agricultor familiar, vive em seu lote com sua família com cultivos
que não exigem muita tecnologia a exemplo da goiaba. Assim, verifica-se que todos
os órgãos criados na região são instrumentos do Estado para atender ao capital
(SOUZA, p. 24, 2006).

A forma de plantar e tipo de mercadoria garantem a chance de trazer prejuízos para os produtores, as instituições tinham o objetivo de diminuir a saída de pessoas para o Sul em buscas de melhores condições. Ainda "Em 1967, a Comissão foi reestruturada. Passou a se chamar SUVALE - Superintendência do Vale do São Francisco, tendo objetivos e atividades bem definidas, a fim de evitar entrechoques com a SUDENE - Superintendência do Desenvolvimento do Nordeste" (GONÇALVES, p. 135, 1997).

\section{Uma análise da paisagem a partir da implantação da mineração na Vila Renascer em Petrolina - PE}

A Vila Renascer, comunidade da Zona Rural do Município de Petrolina, Pernambuco, Nordeste do Brasil, está localizada cerca de $23 \mathrm{~km}$ do centro da cidade (Figura 01). A comunidade tem quarenta anos de existência, sendo constituída por 300 habitantes e cerca de 150 casas.

O perfil socioeconômico da comunidade é de baixa renda de até (1,0 salário mínimo),onde a renda da comunidade é fruto de atividades agrícolas de subsistência e 


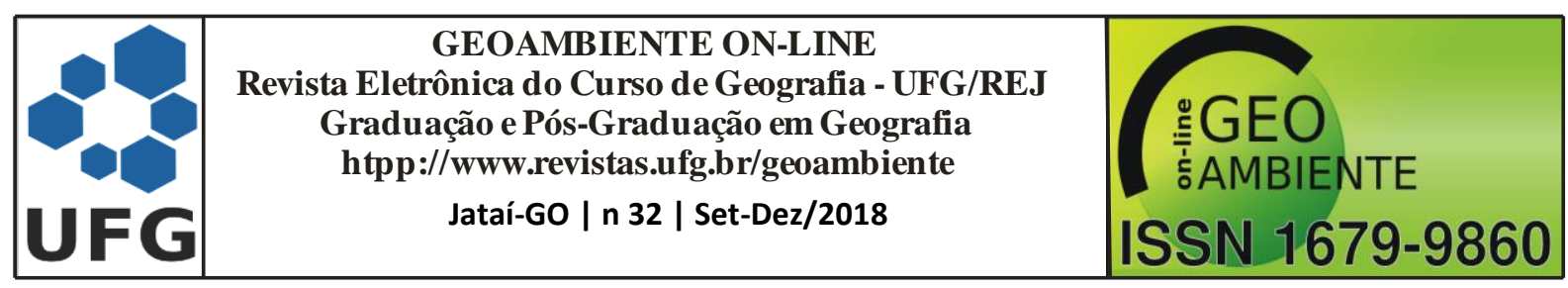

exploração do gnaisse. Para (SILVA, MOURA, SANTOS, 2018), grande parte das pessoas que participaram da entrevista são mulheres (52,8\%) com idade entre 18 a 29 anos (36,7\%). No que diz respeito às condições de moradia/habitação o público alvo entrevistado tem casa própria $(75,6 \%)$.

As atividades econômicas desenvolvidas na Vila Renascer no seu início era da produção de feijão, milho, mandioca e carvão vegetal. A agricultura camponesa garantia o sustento da população que ai habitava, os alimentos plantados e colhidos eram distribuídos entre todos, como fonte alternativa de renda, o carvão vegetal era levado ao mercado público de Petrolina, Pernambuco para venda ou troca por outros produtos.

Figura 01: Área da comunidade da Vila Renascer e da mineração do gnaisse em Petrolina, Pernambuco Nordeste do Brasil.
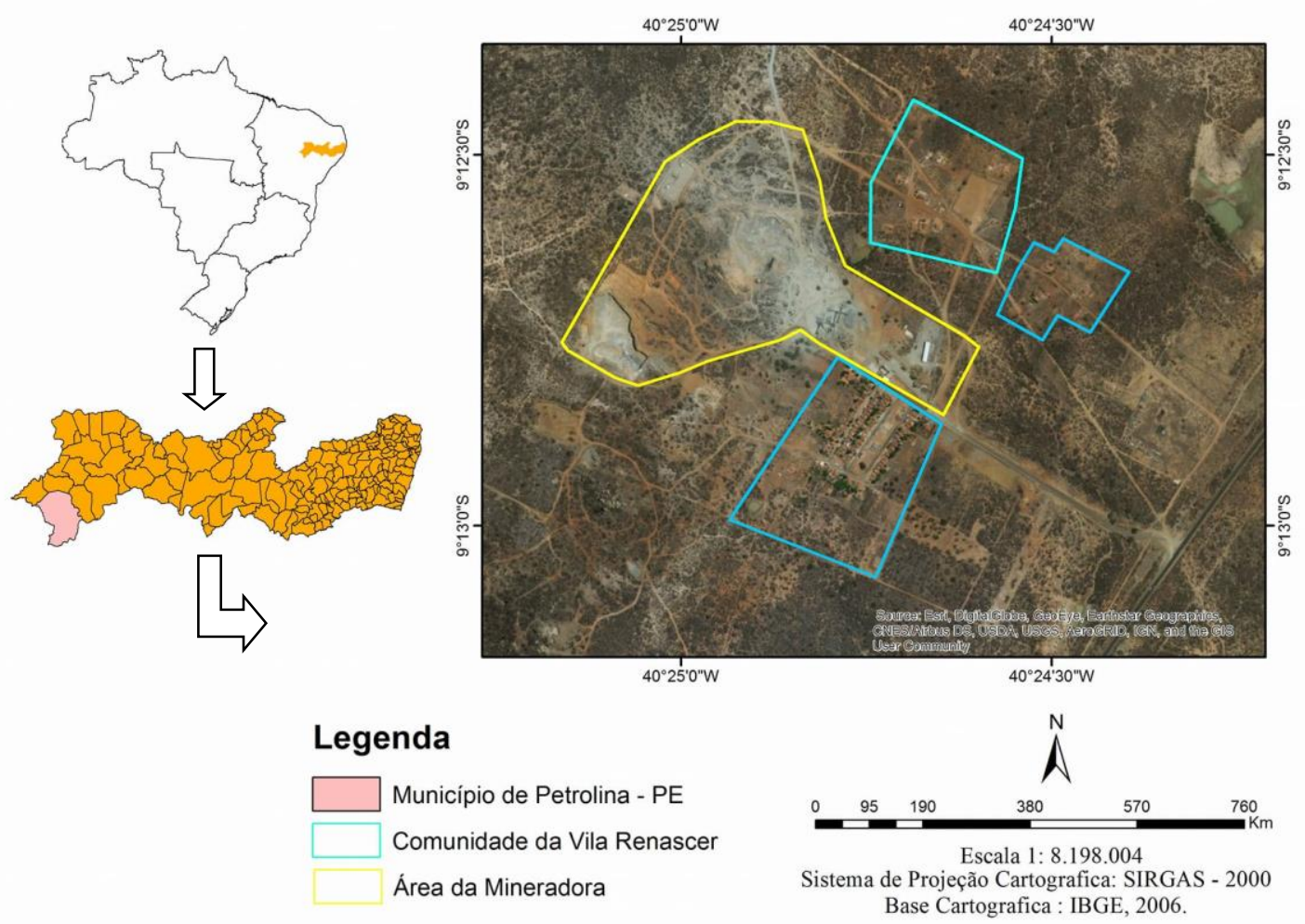

Fonte: Os autores, 2018.

Anteriormente a população da Vila Renascer não residia no local em que a comunidade está hoje inserida, mas sim na área ocupada atualmente pela mineradora, área denominada por todos "pé da serra" como informam os moradores mais antigos da comunidade. A primeira casa construída na comunidade da Vila Renascer, foi de barro 


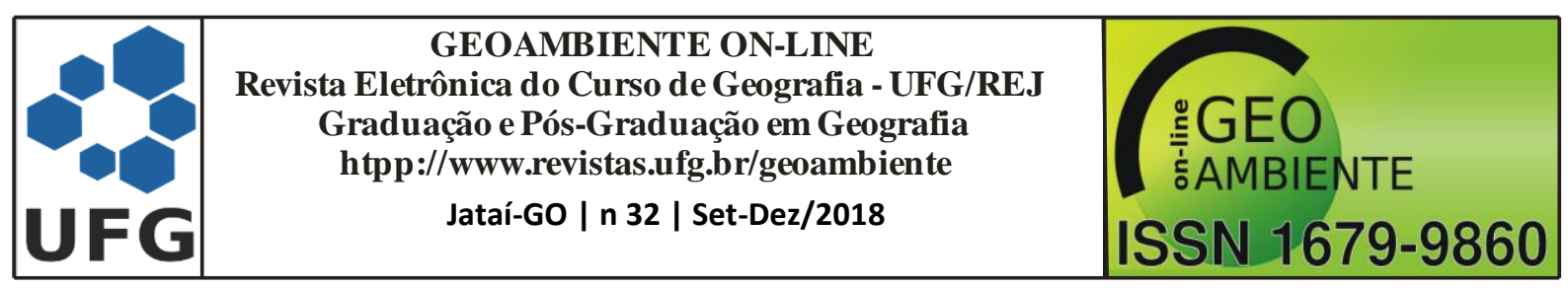

coberta com telha e pertencia ao Sr. Antônio Brandindo um dos primeiros moradores da comunidade, a mesma se encontrava localizada na base da serra (Figura 02).

Figura 02: Primeira casa construída na comunidade da Vila Renascer em Petrolina, Pernambuco, Nordeste do Brasil.

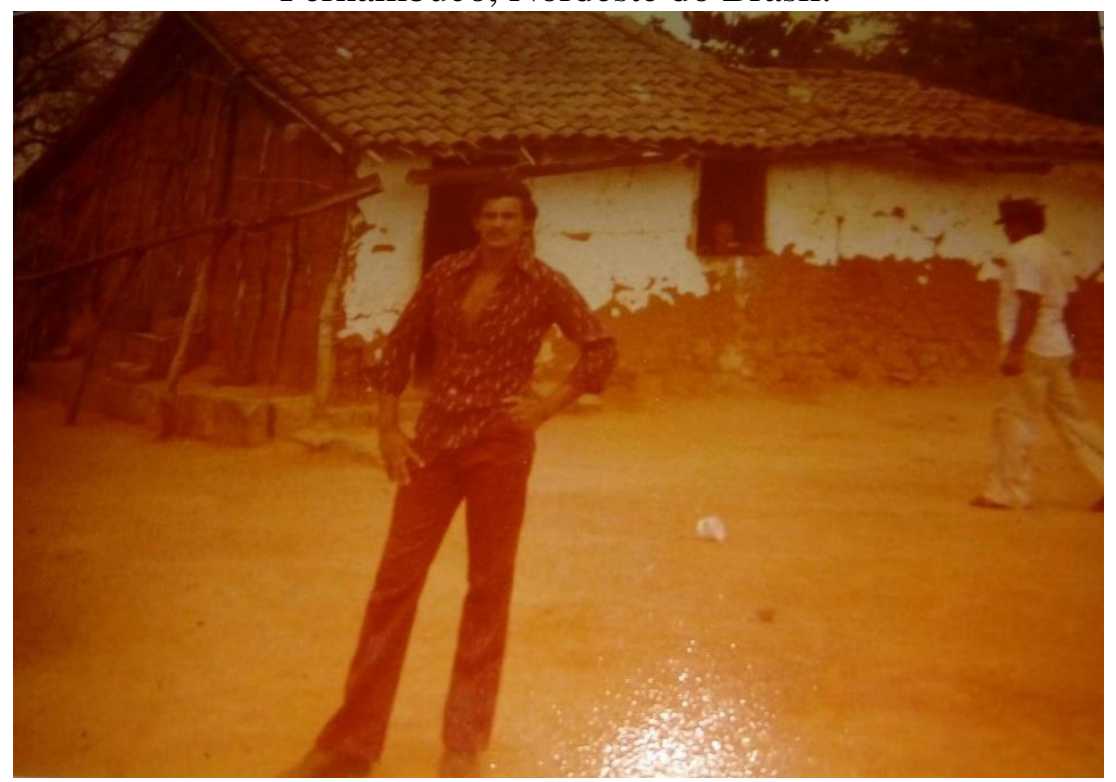

Fonte: Acervo da Família Lima, 1960.

Nesse período, os residentes não sabiam ainda como cortar e explorar economicamente a rocha. A técnica lhes foi ensinada por trabalhadores de empresas de mineração que vieram de São Paulo ao encontro de parentes e passaram a residir na comunidade. A primeira extração da rocha na comunidade da Vila Renascer, a rocha britada (Figura 03), era comercializada na cidade de Petrolina. A locomoção dos trabalhadores entre a Vila Renascer e a cidade de Petrolina, era realizada através de animais domésticos (Figura 04).

As primeiras extrações eram realizadas de maneira rústica e manual, o tipo de rocha selecionado era adequado às exigências do comércio local, entre eles o pó de brita, cascalho, ou pedaços de rochas maiores para paralelepípedo (Figura 05). A extração artesanal de rocha para pavimentação, o paralelepípedo, ganhou destaque como fonte de renda para os agricultores locais, garantindo recursos para a compra de mantimentos. A partir daí a renda proveniente da exploração mineral na comunidade passa a fazer parte da economia local, no entanto, os recursos eram insuficientes para manter as famílias da comunidade. 


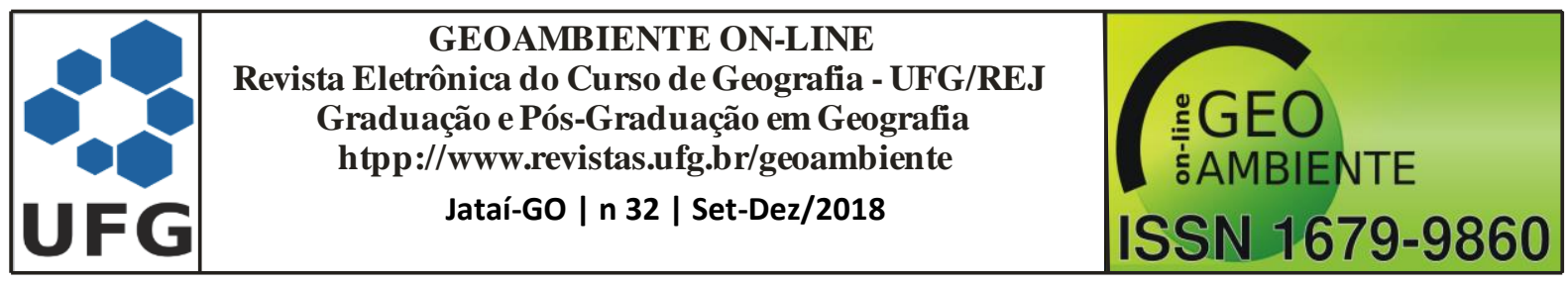

Figura 03: Primeira extração da rocha em forma de brita na comunidade da Vila Renascer, Petrolina, Pernambuco Nordeste do Brasil.

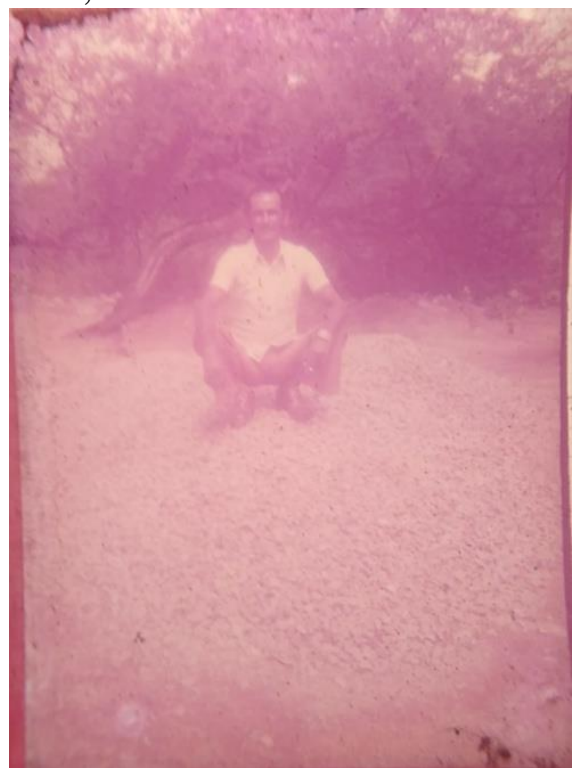

Fonte: Acervo da Família Lima, 1960.

Figura 04: Locomoção por meio de animais na comunidade da Vila Renascer, Petrolina, Pernambuco, Nordeste do Brasil.

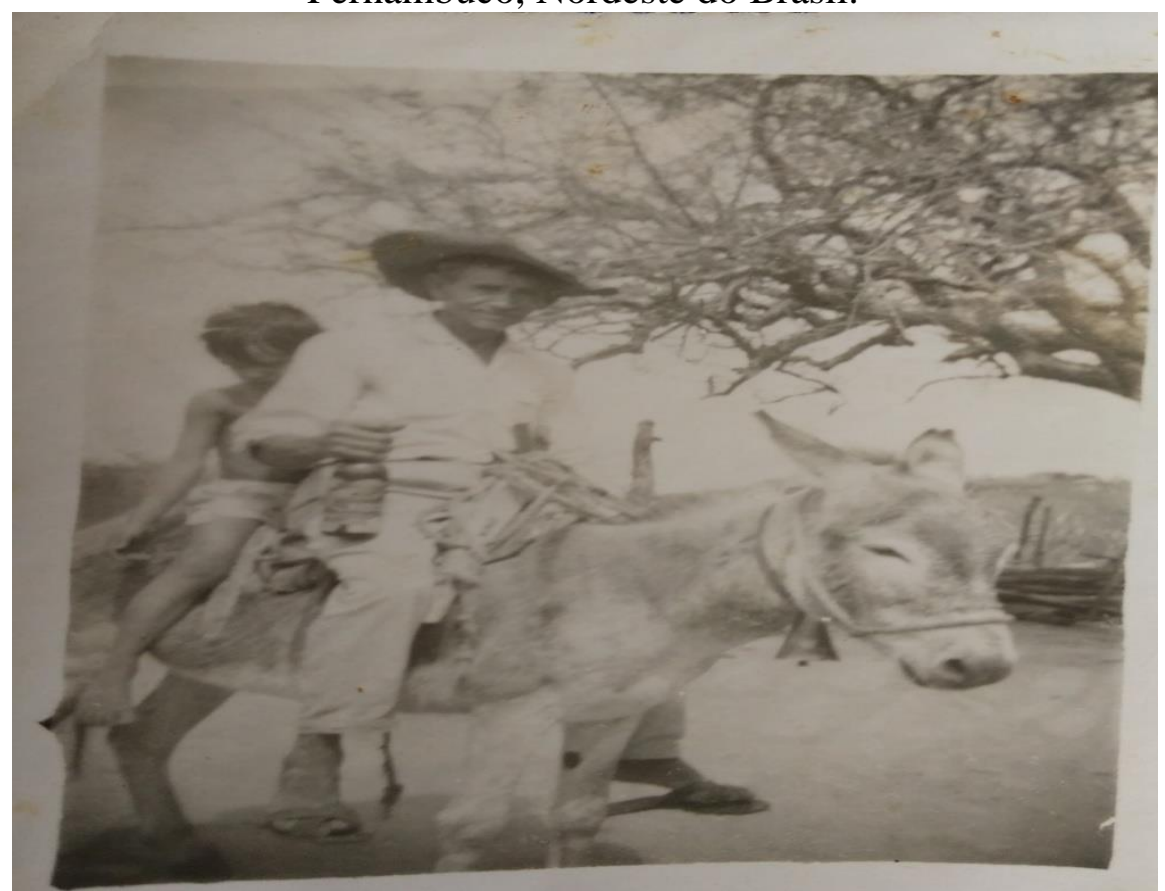

Fonte: Acervo da Família Lima, 1961. 


\begin{tabular}{|c|c|c|}
\hline & $\begin{array}{c}\text { GEOAMBIENTE ON-LINE } \\
\text { Revista Eletrônica do Curso de Geografia - UFG/REJ } \\
\text { Graduação e Pós-Graduação em Geografia } \\
\text { htpp://www.revistas.ufg.br/geoambiente } \\
\text { Jataí-Go | n } 32 \text { | Set-Dez/2018 }\end{array}$ & $\begin{array}{c}\text { : GEO } \\
\text { G.AMBIENTE } \\
\text { G }\end{array}$ \\
\hline
\end{tabular}

Figura 05: Uma das primeiras áreas de exploração do gnaisse na comunidade da Vila Renascer em Petrolina, Pernambuco Nordeste do Brasil.

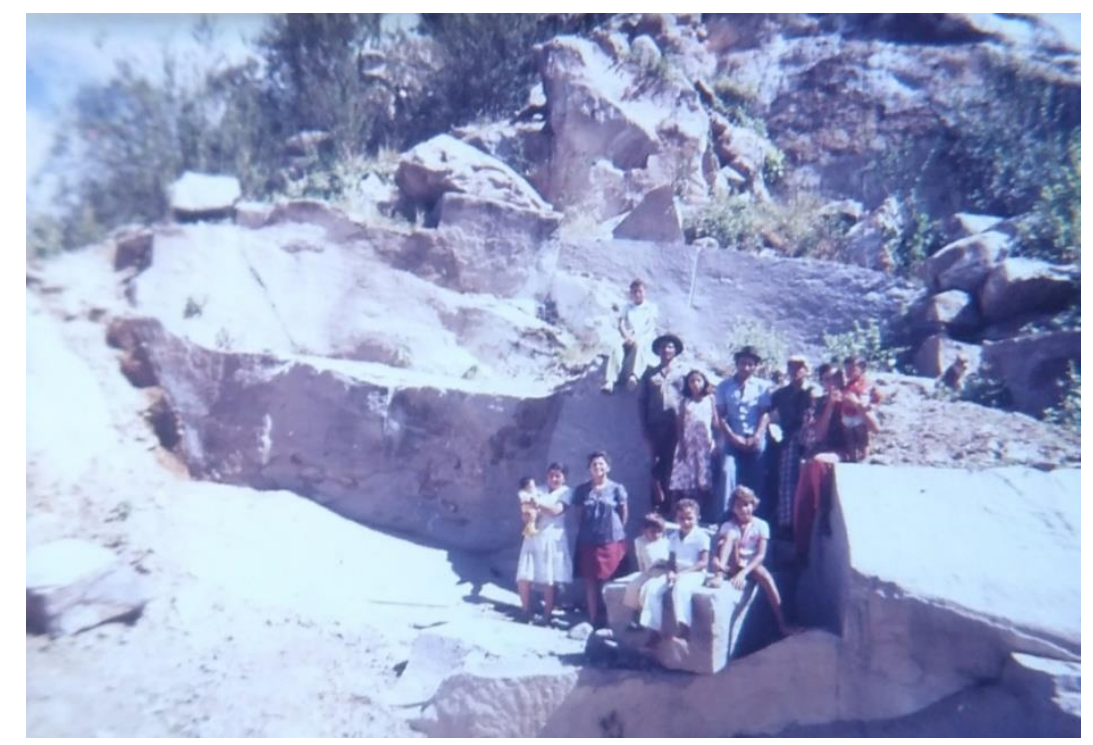

Fonte: Acervo da Família Lima, 1965.

Com a profissionalização da extração mineral, surgem os primeiros impactos ambientais decorrentes dessa exploração. As casas até então feitas de barro, foram substituídas por casas de alvenaria, marcando o desenvolvimento local e transformação da paisagem. Com o passar dos anos, novas técnicas de extração da mineração foram desenvolvidas, ao mesmo tempo, cresciam as áreas de agricultura irrigada em Petrolina, promovendo a migração de moradores para trabalhar nos Projetos Irrigados Nilo Coelho e Bebedouro (Figura 06).

A extração dos recursos naturais minerais, além de criar um cenário transformado na paisagem promoveu a extinção da fauna de espécies como o mocó (Kerodonrupestris), caititu (Pecari tajacu),e flora à catingueira (Caesalpiniapyramidalis) e o umbuzeiro (Spondias tuberosa), em torno da mineradora, com impactos também nas áreas de residências (SILVA, MOURA, SANTOS, 2018). 


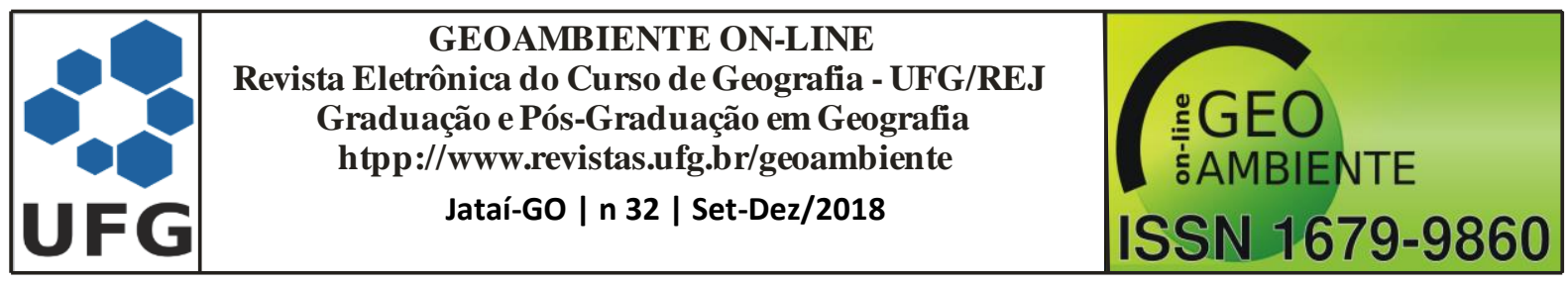

Figura 06: População em frente as suas residências no início da construção da Vila Renascer em Petrolina, Pernambuco, Nordeste do Brasil.

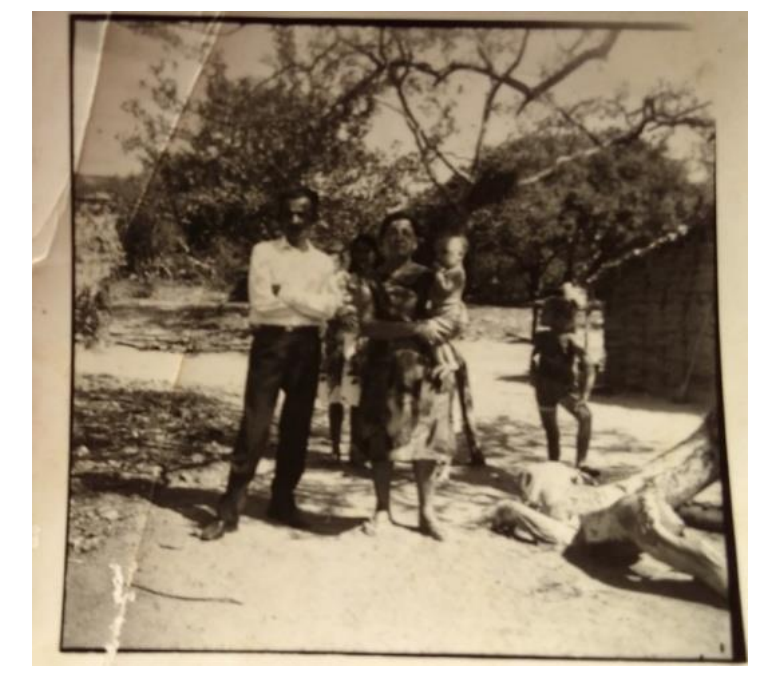

Fonte: Acervo da Família Lima, 1962.

Para Bacci e colaboradores,

Os efeitos ambientais estão associados, de modo geral, às diversas fases de exploração dos bens minerais, como à abertura da cava, (retirada da vegetação, escavações, movimentação de terra e modificação da paisagem local), ao uso de explosivos no desmonte de rocha (sobrepressãoatmosférica, vibração do terreno, ultralançamento de fragmentos, fumos, gases, poeira, ruído), ao transporte e beneficiamento do minério (geração de poeira e ruído), afetando os meios como água, solo e ar, além da população local (BACCI, LANDIM, ESTON, p.48, 2018).

O conceito de paisagem cultural foi adotado em 1992 pela United Nations Educational, Scientificand Cultural Organization (UNESCO) e ratificada atualmente por 186 países. Para a UNESCO, a paisagem cultural contempla uma série de interações entre o homem e seu ambiente natural e reflete técnicas específicas de uso sustentável do solo, considerando as características e os limites do ambiente natural, além de muitas vezes refletir as relações espirituais que determinadas comunidades possuem com a natureza (UNESCO, 2011).

A paisagem não só apresenta as formas geométricas, a cor, os odores, mas também uma história que se desenvolveu em determinado espaço físico, marcado pela produção coletiva das forças, símbolos, cultura e as representação das expressões culturais de um povo no espaço geográfico (MILAGRES, SOUZA, 2012). Neste sentido, as transformações da paisagem na Vila Renascer são perceptíveis, notando-se ao longo do tempo modificações no 


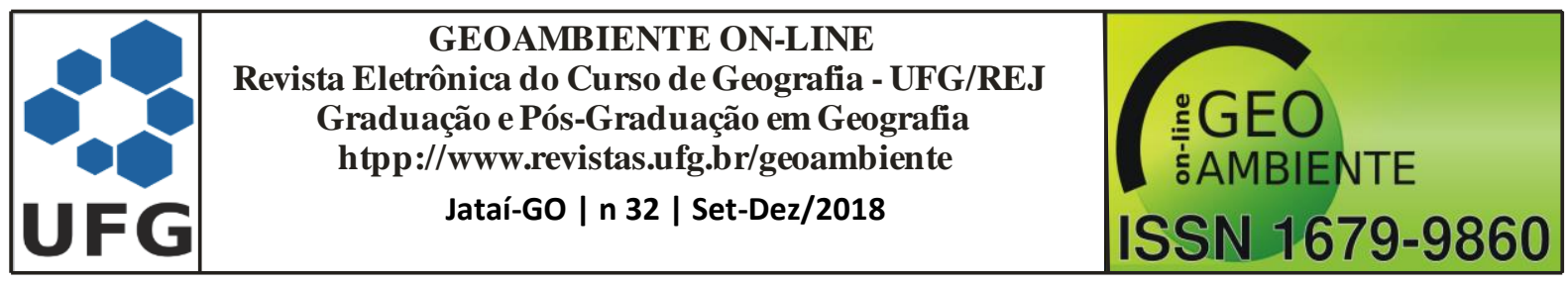

relevo, recursos vegetais e animais, fontes de água e consequentemente alterando a qualidade de vida dos seus moradores.

Os moradores foram expropriados de suas residências, devido aos impactos gerados pelas mineradoras, uma vez que a extração do mineral gera insalubridade pela poeira, gerando inúmeros transtornos na vida e na história da comunidade que teve de afastar-se do território antes ocupado e cultivado, com quem mantinham relações econômicas, e simbólicas.

Pontes, Farias e Lima (2013), evidenciaram que o desmonte de rochas com explosivos causam abalos sísmicos, emissão de gases e poeira, provocando a poluição do ar e ultra lançamento de fragmentos rochosos, como também a perda da flora e da fauna, além da degradação da paisagem.

As residências dos moradores atualmente sofrem vários abalos em sua estrutura provocados pelas explosões (SILVA, MOURA, SANTOS, 2018) (Figura 7).

Figura 07: Casas rachadas por conta da detonação da rocha na comunidade da Vila Renascer em Petrolina, Pernambuco Nordeste do Brasil.

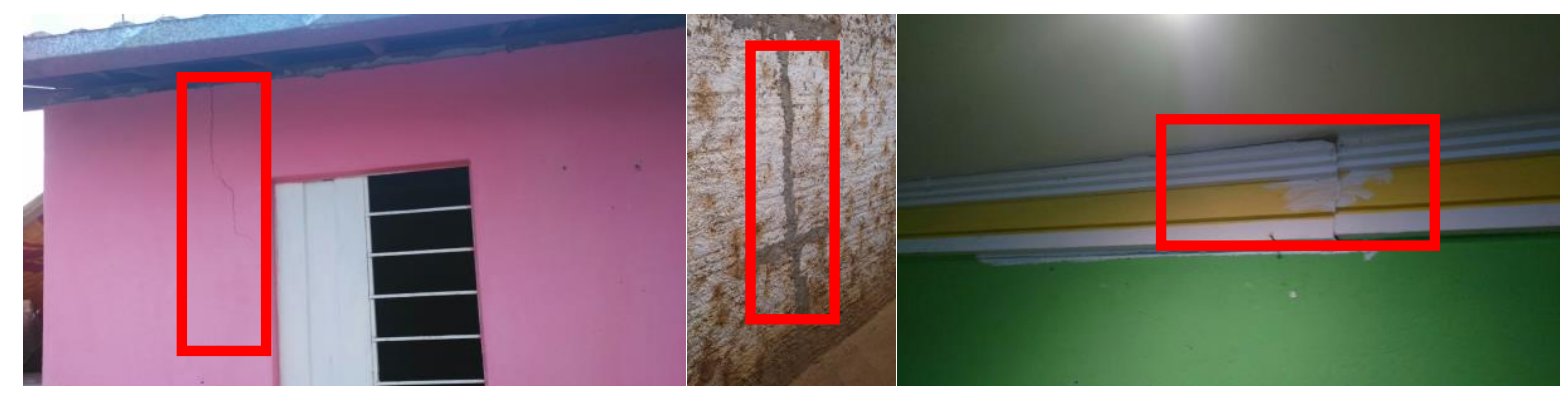

Fonte: Os autores,2017.

As famílias residentes, vivem isoladas, carentes de atenção por parte do poder público para o atendimento dos serviços básicos essenciais. A ausência de postos de saúde, transporte, escolas públicas, entre outros, direitos assegurados pela Constituição Federal em 1988, no Artigo $5^{\circ}$ que "garante a todos os brasileiros e naturalizados o direito à moradia, saúde, educação, trabalho e segurança", até o momento estes direitos não se aplicam aos moradores da Vila Renascer, a população local precisa se deslocar em busca de atenção básica à saúde educação em outros núcleos do Perímetro Irrigado Nilo Coelho, tornando difícil a permanência dos mesmos em seu território físico e simbólico. 


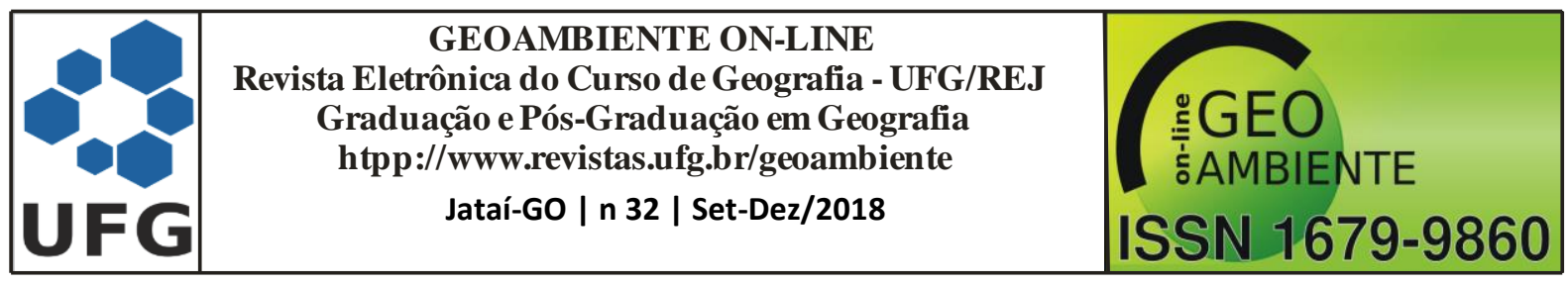

Agravando esta situação, enfrentam a possibilidade de encerramento das atividades da empresa mineradora, principal fonte de renda das famílias desta localidade.

Neste sentido, observamos a transformação sócio espacial na comunidade da Vila Renascer, pois a atividade da mineração nesse espaço aprofundou as desigualdades, também a anulação do sujeito na sua condição como agente de produção desse espaço. Diante do exposto, a paisagem como também toda a dinâmica do meio ambiente é alterada após a atividade da mineração neste espaço, pois a retirada da vegetação nativa vai causar a degradação dessas áreas, impactos na paisagem local, extinção de espécies da caatinga, transtornos na saúde da população e também depredação de patrimônio particular (a várias marcas nas estruturas das residências pelo uso de explosivos, assim acometendo a estrutura das residências com rachaduras).

Ainda, a necessidade de fortalecimento da economia da comunidade, pois a maior parte da renda é de empregos na mineração, pensar o desenvolvimento de outras atividades é fundamental, pois a mineração no Brasil deixou muitas áreas degredadas e sem condições de reprodução da vida para a população.

\section{CONSIDERAÇÕES FINAIS}

Diante do apresentado observou-se que a construção e transformação do espaço deu-se a partir do desenvolvimento das técnicas que contribuem para o trabalho e criação de novas cidades e vilas como ocorreu na história do Brasil.

Na região do submédio São Francisco, com a chegada dos colonizadores em busca de recursos minerais para obtenção da riqueza, observando que os solos da região são extremamente férteis, deram início a práticas agrícolas e criação animal. A exploração de minérios foi iniciada a partir da chegada de mineradores da região Sudeste do país. Assim, contribuiu para o crescimento e desenvolvimento da comunidade da Vila Renascer melhorando de certa forma a vida da população economicamente.

Deste momento em diante, a transformação espacial do território ocupado pela comunidade da Vila Renascer, ocorre de forma acelerada com a exploração da mineração do gnaisse. Atualmente o esgotamento dos recursos minerais no solo, consequência da ausência de um planejamento da empresa mineradora, promoveu a alteração radical da paisagem, gerando perda da biodiversidade local (SILVA; MOURA; SANTOS, 2018), com 


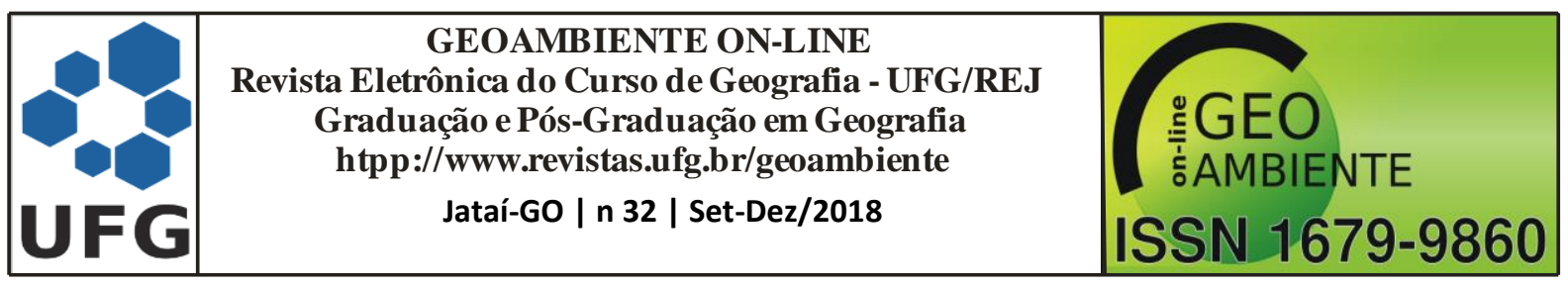

repercussões negativas na vida da sociedade local, que relegada a segundo plano pela administração pública municipal, vive desassistida dos serviços essenciais à manutenção da qualidade de vida humana, como saúde, educação, alimentação e fonte de renda.

\section{Agradecimentos}

Agradecemos a Coordenação de Aperfeiçoamento de Pessoal de Nível Superior (CAPES) pela concessão da bolsa de estudos ao primeiro autor, durante o mestrado.

\section{REFERÊNCIAS}

ANDRADE, U. M. Um rio de histórias a formação da alteridade Tumbalalá e a rede de trocas do submédio São Francisco. 319 f. Dissertação (Programa de Pós-Graduação em Antropologia Social), Faculdade de Filosofia, Letras e Ciências Humanas da Universidade de São Paulo, 2002.

BACCI, D. L. C.; LANDIM, P. M. B.; ESTON, S. M. Aspectos e impactos ambientais de pedreira em área urbana. Revista Escola de Minas,Ouro Preto, v. 59, n. 1, 2006.

CARLOS, A. F. A. A cidade, $8^{\text {a }}$ ed. $1^{\text {a }}$ reimpressão, São Paulo, Contexto, 2007.

COSTA, E. B. Totalidade urbana e totalidade-mundo: as cidades coloniais barrocas face à patrimonialização global. 427 f. Tese (Programa de Pós-Graduação em Geografia Humana), Faculdade de Filosofia, Letras e Ciências Humanas da Universidade de São Paulo, 2011.

FURTADO, A.; STAHEL, A.; RIBEIRO, A.; MENDES, A.; SEKIGUCHI, C.; CAVALCANTI, C.; MAIMON, POSEY, D. D.; PIRES, E.; BRÜSEKE, F.; ROHDE, G.; MAMMANA, G.; LEIS, H.; MEDEIROS, H. A. J.; D'AMATO, J. L.; LEONARDI, M. L.; TOLMASQUIM, M.; FILHO, O. S.; STROH, P.; FREIRE, P.; MAY, P.; DINIZ,R.; MAGALHÃES, A. R. Desenvolvimento e natureza: estudos para uma sociedade sustentável. INPSO/FUNDAJ, Instituto de Pesquisas Sociais, Fundação Joaquim Nabuco, Ministério de Educação, Governo Federal, Recife, Brasil. p. 262, 1994.

GONÇALVES, E. L. Opará formação histórica e social do Submédio do São Francisco, Gráfica Franciscana, Petrolina 1997.

MILAGRES, V. R.; SOUZA L. B. Ensaio sobre a paisagem e o turismo: uma viagem além das disciplinas. Revista Geografia (Londrina),v. 21, n. 1, p.37-64, 2012. 


\begin{tabular}{|c|c|c|}
\hline & $\begin{array}{c}\text { GEOAMBIENTE ON-LINE } \\
\text { Revista Eletrônica do Curso de Geografia - UFG/REJ } \\
\text { Graduação e Pós-Graduação em Geografia } \\
\text { htpp://www.revistas.ufg.br/geoambiente } \\
\text { Jataí-Go | n } 32 \text { | Set-Dez/2018 }\end{array}$ & $\begin{array}{c}\text { : GEO } \\
\text { G.AMBIENTE } \\
\text { G }\end{array}$ \\
\hline
\end{tabular}

OLIVEIRA, R. S.; SANTOS, J. L. As políticas de desenvolvimento do Nordeste: os Distritos Irrigados Bebedouro e Senador Nilo Coelho, no município de Petrolina no estado de Pernambuco.Anais...In: VI Simpósio Internacional de Geografia Agrária, V Simpósio Nacional de Geografia Agrária. Niterói- RJ.p.1-12, 2009.

ORTEGA, A. C.; SOBEL, T. F. Desenvolvimento territorial e perímetros irrigados: avaliação das políticas governamentais implantadas nos perímetros irrigados Bebedouro e Nilo coelho em Petrolina (PE). Planejamento e políticas públicas, n. 35, p. 87-118, 2010.

PONTES, J. C.; FARIAS, M. S. S.; LIMA, V. L. A. Mineração e seus reflexos socioambientais: estudo de impactos de vizinhança (EIV) causados pelo desmonte de rochas com uso de explosivos. Revista Polêmica, v. 12, n. 1, p. 77-90, 2013.

RIOS, M. I. F. A dependência como pressuposto do contrato de trabalho: ontem, hoje e provável amanhã, uma leitura atemporal.441f. Dissertação (Programa de Pós-Graduação em Direito), Pontifícia Universidade Católica de Minas Gerais, 2011.

SILVA, F. P.; MOURA, G. J. B. SANTOS, C. A. B.Representações dos moradores do entorno das áreas de exploração sobre a importância e impactos da mineração. Geosul, Florianópolis, v.33, n. 66, p.128-146, 2018.

SOUZA. R. Á. D. O processo de expansão do capitalismo no campo, o agronegócio e a resistência da unidade de produção familiar: o caso do projeto Senador Nilo Coelho Petrolina PE. São Cristóvão - Universidade Federal de Sergipe. 2006.

SCHNEIDER, W. C. História das cidades: de Babilônia a Brasília, Rio de Janeiro, Nova Fronteira, 370 p.,1965.

TRES, D. R.; REIS, A.; SCHLINDWEIN, S. L. A construção de cenários da relação homemnatureza sob uma perspectiva sistêmica para o estudo da paisagem em fazendas produtoras de madeira no planalto norte catarinense. Ambiente \& Sociedade. v. 14, n. 1, p. 151-173, 2011. UNESCO. 2011. World Heritage Convention. Disponível em<:http://whc.unesco.org/archive/convention-pt.pdf. Acesso em>: 25 janeiro 2018. 